\title{
Uma proposta para a introdução do ensino de Funções através da utilização do programa Tracker
}

\author{
A proposal for the introduction of the teaching of functions through the use of the \\ Tracker.
}

\author{
Renata Magarinus ${ }^{1}$, Lidiane Buligon² e Márcio Marques Martins ${ }^{3}$ \\ ${ }^{1}$ Mestre em Matemática, Professora da E.E. Raimundo Corrêa - Ernestina, RS. \\ renatamagarinus@bol.com.br
}
${ }^{2}$ Professora Doutora do Centro de Ciências Naturais e Exatas - Universidade Federal de Santa Maria - UFSM prof.buligon@gmail.com
$\mathrm{ZZ}$
${ }^{3}$ Professor Doutor da Universidade Federal do Pampa - UNIPAMPA
marsjomm@gmail.com

\begin{abstract}
Resumo
O presente trabalho tem como objetivo apresentar uma proposta para a introdução e exploração de alguns conceitos presentes no estudo de funções afins e quadráticas. Acreditando que a contextualização dos conteúdos e a interdisciplinaridade corroboram para a aprendizagem significativa da matemática, nosso trabalho propõe uma sequência de atividades que, a partir de problemas reais, pretende explorar alguns conceitos presentes no estudo de funções afins e quadráticas. Para auxiliar os alunos na resolução dos problemas e na exploração destes conceitos, utilizamos o software Tracker. Acreditamos que esta proposta poderá contribuir para a melhoria da qualidade do ensino da matemática e mais especificamente para o ensino de funções.
\end{abstract}

Palavras-chave: Ensino e aprendizagem da matemática. Ensino de funções. Resolução de problemas. Tracker.

\begin{abstract}
The present work aims to present a proposal for the introduction and exploration of the some concepts in the study of affine and quadratic functions. Furthermore, believing that contextualization of content and interdisciplinarity to corroborate the significant learning of mathematics, our work proposes a sequence of activities from, real problems will explore the some concepts in the study of affine and quadratic functions. To assist students in solving problems and exploring these concepts and use the software Tracker. We believe that this proposal will contribute to improving the quality of mathematics teaching and more specifically for teaching functions.
\end{abstract}

Keywords: Teaching and learning of mathematics. Teaching functions. Problems solving. Tracker. 


\section{Introdução}

Dentre os conteúdos matemáticos estudados na educação básica, o estudo de funções ocupa lugar de destaque. Sua relevância pode ser justificada pelo fato de que o conceito de função estabelece relações com vários outros conceitos matemáticos e pode ser aplicado no estudo de fenômenos em diversas áreas do conhecimento.

Segundo os Parâmetros Curriculares do Ensino Médio, o estudo de funções deve possibilitar ao aluno flexibilidade para lidar com o conceito de função em situações diversas, buscando a solução de situaçõesproblema de matemática e de outras áreas, adequando seus conhecimentos sobre funções para construir um modelo de interpretação e investigação em matemática. (BRASIL, 2000, p. 257).

Nossa prática como professora de matemática na educação básica demonstra que o ensino de funções não vem garantindo aos alunos sua efetiva aprendizagem. Após uma pesquisa realizada com alunos do ensino médio (MAGARINUS, 2006), verificamos que a maioria dos alunos apresenta dificuldade em expressar suas ideias sobre o que representa uma função e qual o seu significado. Tal pesquisa nos levou a acreditar que o estudo de funções não proporcionou o desenvolvimento cognitivo dos alunos e a construção do conhecimento, além de ser realizado de maneira descontextualizada e pouco significativa.

A leitura de vários trabalhos já desenvolvidos relacionados à aprendizagem dos conceitos presentes na matemática e, mais especificamente no estudo de funções, nos mostrou a importância da construção do conhecimento, contextualização dos conteúdos e a interdisciplinaridade.

Contudo, sentimo-nos motivados a elaborar uma proposta para a introdução e exploração dos principais conceitos presentes no estudo de funções afins e quadráticas para alunos do ensino médio. Tal proposta originou a dissertação de mestrado intitulada “Uma proposta para o ensino de funções através da utilização de objetos de aprendizagem". Neste artigo, apresentamos uma parte deste trabalho, o qual propõe uma sequência de duas atividades, que a partir de situaçõesproblema, introduz de maneira significativa e gradativa tais conceitos. Para auxiliar os alunos na resolução dos problemas e na exploração dos conteúdos, vamos utilizar o software Tracker.

O Tracker, software destinado à análise de vídeos do ponto de vista físico, utilizado nas atividades, terá como principal objetivo explorar intuitivamente o conceito de função e a relação entre as variáveis.

Acreditamos que a proposta aqui apresentada atende à necessidade de um ensino da matemática mais significativo, voltado à participação do aluno na construção de seus conhecimentos, contribuindo efetivamente para a apropriação do saber matemático. Esta crença pode ser fundamentada nas escolhas metodológicas e no modo como as atividades foram elaboradas. A escolha do software, a metodologia de resolução 
de problemas e o contexto das situações apresentadas possibilitaram uma maior exploração dos aspectos relacionados ao estudo de funções de um modo dinâmico e significativo.

\section{Alguns aspectos considerados relevantes na elaboração das atividades}

A partir de uma pesquisa investigativa (MAGARINUS, 2006), realizada com alunos do ensino médio de duas escolas estaduais que já haviam estudado funções em anos anteriores, verificou-se que os alunos não tinham assimilado grande parte dos conhecimentos referentes ao estudo de funções.

Diante desta realidade, nos sentimos desconfortáveis em relação a nosso modo de ensinar. Após várias leituras, percebemos que nossas constatações também eram comuns a outras pesquisas realizadas a respeito dos conhecimentos de alunos e também de professores sobre o estudo de funções. (ZUFFI, PACCA, 2000; COSTA, A., 2004; MARIANI, 2004; COSTA, C., 2008).

Tais pesquisas nos motivaram a elaborar uma proposta para a introdução do estudo de funções para alunos do ensino médio, a fim de proporcionar aos colegas professores uma nova alternativa para o ensino de funções.

A partir dos resultados de algumas pesquisas e da realização de uma revisão teórica sobre o estudo de funções, delineamos alguns aspectos que julgamos importantes e que deveríamos nos ater na elaboração das atividades.

O primeiro aspecto diz respeito ao próprio conceito de função. Nossos estudos indicam que a compreensão deste conceito é determinante para o aprendizado dos demais conceitos matemáticos relacionados ao estudo de funções.

Segundo nossa pesquisa, os alunos "[...] têm uma visão estática do conceito de função, tendo a ideia de que uma função só tem razão de existir na própria matemática, [...] ficando evidente que os alunos associam a função a uma equação ou fórmula, cujo objetivo é descobrir os valores de $\mathrm{x}$ e y para construir gráfico." (MAGARINUS, 2006, p. 62-63). Observamos que os alunos não desenvolvem a noção de variação e dependência, que é a base do conceito de função, e não percebem a importância deste conceito fora do âmbito matemático. Outras pesquisas também destacam que os alunos apresentam deficiências no campo conceitual de função. (OLIVEIRA, 1997, p. 57; MARIANI, 2004, p. 49; COSTA, 2004, p. 52-53).

Além disso, verificamos que na representação algébrica os alunos também não estabelecem a relação entre as variáveis e demonstram dificuldades em diferenciar equação de uma função. Para eles, qualquer equação, desde que tenha duas letras, é um exemplo de função. (MAGARINUS, 2006, p. 42; MARIANI, 2004, p. 50; ZUFFI, 2001, p. 15)

Em relação à representação gráfica, verificamos, em nossa pesquisa (MAGARINUS, 2006), que os alunos demonstram não ter clareza do que 
define uma função e das condições necessárias para que um gráfico represente uma relação funcional ( $p$. 46).

A partir de tais constatações, verificamos que o estudo de funções deve resgatar os componentes de variação e relação de dependência e, além disso, deve-se trabalhar o conceito de função de modo dinâmico, proporcionando aos alunos uma noção intuitiva de função a partir de problemas práticos.

Tomando por base estas constatações, elaboramos uma sequência de atividades relacionadas à fenômenos físicos e mais especificamente ao movimento dos corpos, uma vez que este assunto também é estudado no $1^{\mathrm{o}}$ ano do ensino médio. Além disso, iniciar o estudo de funções através de questões da Física mostra aos alunos o aspecto dinâmico deste conceito e sua importância para outras áreas do conhecimento, além de cumprir com uma das expectativas do ensino atual que é a interdisciplinaridade.

Para explorar os aspectos físicos das situações-problema propostas aos alunos e introduzir de modo dinâmico o conceito de função, decidimos trabalhar com o software Tracker. Pretende-se, através deste programa, envolver os alunos durante todo o processo de realização das atividades e a partir daí construir o conceito de função.

Na proposta didática, o Tracker possibilitará a análise física dos movimentos dos corpos filmados pelos alunos, fornecendo tabelas de valores e diversos tipos de gráficos relacionando a posição do móvel no decorrer do tempo e a velocidade em função do tempo, entre outros.

Desta maneira, sugerimos neste trabalho a análise do movimento de uma bola de tênis em duas situações: sendo largada de uma determinada altura e arremessada para o alto. Dependendo do grau de envolvimento da turma, poderão surgir outras ideias em relação à filmagem e ao objeto utilizado.

O desenvolvimento da primeira atividade com o uso do Tracker tem como objetivos construir a noção intuitiva de função, que se dará através da relação de dependência entre as variáveis envolvidas no fenômeno estudado; introduzir seu aspecto variacional através da análise gráfica; estudar aspectos gráficos de uma função, como crescimento e decrescimento.

Para a realização da segunda atividade, propomos outra situaçãoproblema. Nesta situação, a análise do movimento do objeto terá como objetivos: abordar novamente a noção de função, evidenciando a relação entre as variáveis dependentes e independentes; introduzir a ideia de função afim e quadrática; identificar diferentes maneiras de representar uma relação funcional, através de gráficos e tabelas, mostrando a possibilidade de transitar entre elas; a partir dos aspectos gráficos fazer $\mathrm{o}$ aluno perceber as diferenças entre uma função afim e quadrática; levar o aluno a conjecturar a representação gráfica de determinados movimentos; através da análise gráfica, introduzir os conceitos de ponto máximo e ponto mínimo, intervalo de crescimento e decrescimento, simetria 
da parábola; explorar o conceito de função injetiva a partir da análise do comportamento das funções afim e quadrática.

Muitos dos aspectos das funções que pretendemos trabalhar com estas atividades seriam difíceis de abordar apenas com o uso de lápis e papel, e mesmo que os livros didáticos atuais tragam muitas informações e imagens, nada se compara à possibilidade do aluno interagir com o objeto de estudo. Além disso, introduzir um conteúdo matemático a partir de um problema prático pode torná-lo mais atraente e enriquecedor para o aluno, uma vez que possibilita vários momentos de descoberta.

Adicionalmente, pretendemos incentivar os alunos a escrever sobre suas observações em relação aos problemas propostos nas atividades. Desta forma, é importante que cada aluno registre por escrito suas respostas, observações e conclusões. Estes registros poderão servir, num segundo momento, como instrumento de avaliação da proposta.

Uma possível dificuldade dos alunos em relação ao desenvolvimento das atividades, pode ser o momento de elaboração das justificativas solicitadas em algumas questões e na elaboração de suas conclusões. Para tanto, sugerimos que as atividades sejam realizadas em duplas ou pequenos grupos e que sejam disponibilizados momentos para discussões também com o grande grupo. Acreditamos que os alunos se sentirão mais encorajados a formular seus registros se suas ideias puderem ser socializadas com os colegas.
Em relação ao tempo previsto para a realização das atividades, supomos ser necessário no mínimo quatro horas para desenvolver cada atividade. Mas, sabendo da diversidade de fatores que influencia a execução de uma proposta, acreditamos que em determinados casos o tempo estimado pode ser muito maior.

Para realizar as atividades, é necessário dispor de uma câmera digital e de alguns computadores, nos quais deverão estar instalados o programa Tracker.

O programa Tracker é uma aplicação gráfica em JAVA construída na Open Source Physics (OSP), comunidade científica que desenvolve e disponibiliza gratuitamente recursos para o ensino de Física e de modelagem computacional. Este software é destinado à análise de vídeos do ponto de vista físico, podendo ser uma ferramenta para modelagem. Através dele, é possível estudar diversos tipos de movimento a partir de filmagens feitas com câmeras digitais.

O programa Tracker e as informações necessárias para sua instalação e utilização, podem ser obtidas no endereço eletrônico: http://www.if.ufrgs.br/cref/uab/lab/tracker.html

\section{Apresentaremos a seguir} algumas atividades que compõem nossa proposta e os objetivos de cada uma delas. 


\section{Sequência de atividades desenvolvidas}

As questões presentes em nossa proposta visam garantir que o aluno faça parte do processo de construção do seu saber e não apenas assuma um papel de mero espectador, o qual recebe de maneira pronta e acabada todo conhecimento. Neste sentido, o professor, ao conduzir as atividades, deverá fazê-las de modo a envolver os alunos através de questionamentos e discussões, o que, acreditamos, levará ao desenvolvimento gradativo dos conceitos que cercam o estudo de funções.

\subsection{A primeira atividade}

A primeira atividade será delineada a partir de um problema sugerido pelo professor e discutido pelos alunos a respeito do comportamento da velocidade de um objeto em queda livre solto de alturas diferentes - aqui utilizaremos como objeto uma bola de tênis. Para auxiliar nas discussões os alunos devem realizar a filmagem do objeto em queda livre de três alturas diferentes.

O programa Tracker fará a análise dos três vídeos, fornecendo vários gráficos referentes ao fenômeno estudado, como por exemplo, o gráfico da intensidade da aceleração e da energia cinética em função do tempo. Considerando que o nosso interesse neste momento é fazer com que o aluno perceba a relação entre a altura de um objeto em queda livre e sua velocidade ao tocar o solo, vamos analisar somente dois gráficos. O primeiro é o gráfico que mostra a componente $y$ da posição da bola no decorrer do tempo e o outro a velocidade da bola durante o tempo de queda.

$\mathrm{Na}$ figura 1, temos ao centro a imagem de um dos vídeos e à direita os dois gráficos mencionados. Os alunos devem assistir aos vídeos e acompanhar o movimento da bola em queda livre. $\mathrm{O}$ programa faz uma sincronia entre o movimento da bola em queda livre, através das marcações realizadas, e a construção dos dois gráficos em questão.

Na sequência, os alunos deverão iniciar uma nova etapa que consiste em responder a uma série de questões a partir da observação dos vídeos e dos dois gráficos gerados pelo programa Tracker. Estas questões têm como finalidade construir o conceito de função através da relação de dependência entre variáveis. 


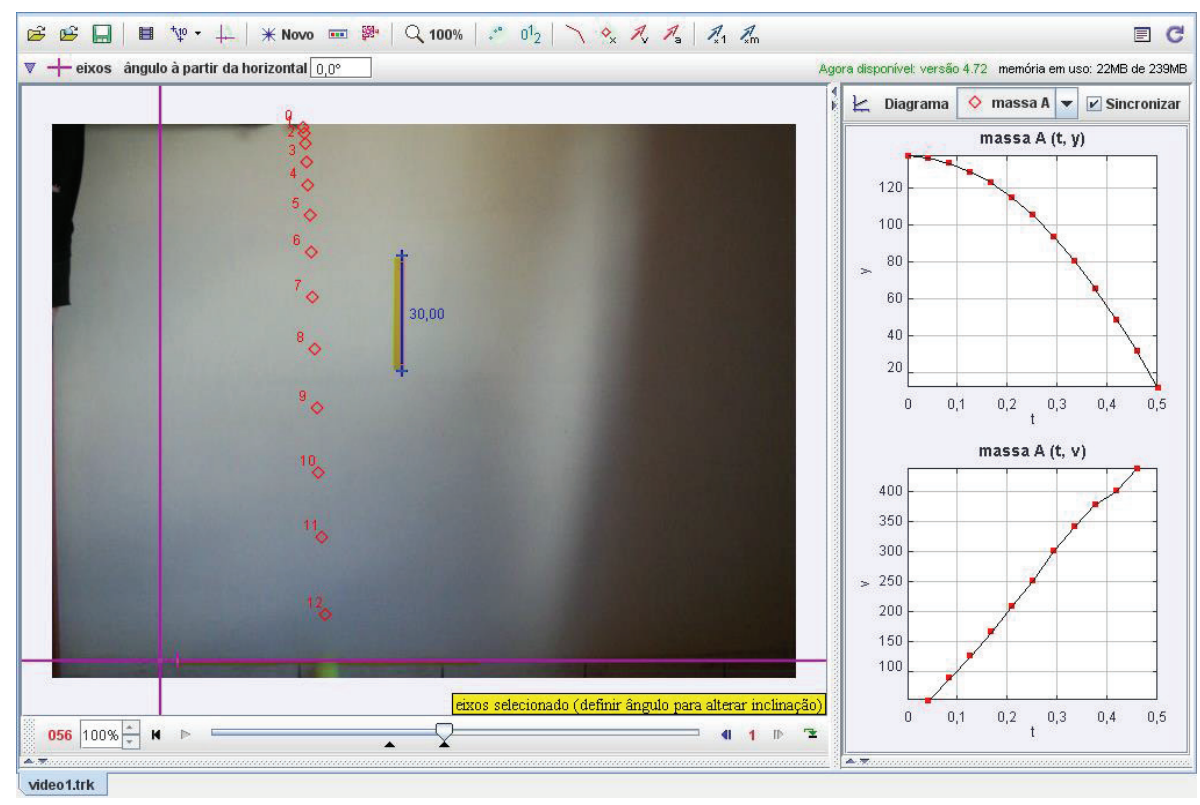

Figura 1 - Análise do movimento do vídeo 1

Questão 1 - A partir da análise dos vídeos e dos gráficos gerados pelo software nas três situações, responda:

a) Considerando que o eixo ilustrado no vídeo seja do plano cartesiano, o que podemos dizer a respeito do eixo vertical? O que ele nos informa?

b) Observando agora o primeiro gráfico: em relação ao eixo vertical, o que ele nos informa? E o eixo horizontal?

c) Analise o segundo gráfico. $\mathrm{O}$ que os eixos verticais e horizontais nos informam?

A questão 1 pretende iniciar com os alunos uma discussão a respeito dos eixos cartesianos e como estes se relacionam entre si. Devemos deixar claro aos alunos que os eixos verticais e horizontais podem referir-se a grandezas diferentes. Destacamos isso, pois é muito provável que estes alunos, no último ano do ensino fundamental, tenham estudado, nas aulas de matemática, a representação gráfica de funções matemáticas elementares, cujos eixos representavam números reais $\mathrm{e}$ não grandezas físicas.

Os alunos deverão perceber que o plano cartesiano tem a função de ajudar a interpretar também fenômenos físicos, como o estudo dos movimentos, ou seja, devem perceber que a matemática está servindo de instrumento para o estudo do movimento de um corpo em queda livre.

As questões que seguem terão como finalidade ajudar os alunos a perceber a relação entre variáveis. Para isso os alunos devem analisar o gráfico que relaciona a posição da bola e o tempo.

\section{Questão 2 - Observando o} primeiro gráfico de cada uma das três situações, conforme exemplificado na figura 2, você seria capaz de dizer de que altura a bola foi lançada em cada uma delas? E qual o respectivo tempo de queda da bola? 


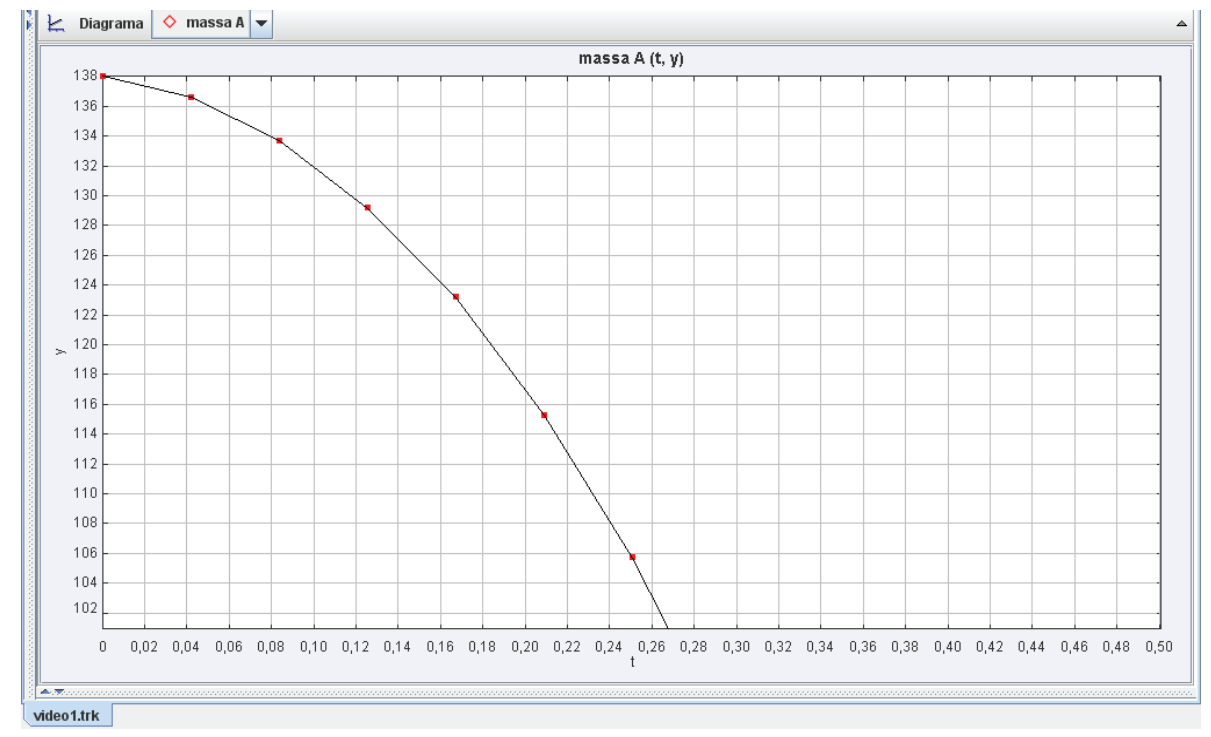

Figura 2 - Gráfico da posição da bola em função do tempo de queda.

Questão 3 - Observando o gráfico da altura da bola no decorrer do tempo responda:

a) Observe os primeiros gráficos de cada uma das situações. A cada intervalo de tempo de $0,02 \mathrm{~s}$ a posição da bola vai modificando. Você pode afirmar que a bola percorre sempre a mesma distância a cada intervalo de tempo? Justifique sua resposta.

b) Em que intervalo de tempo a bola percorre menor distância? E em que intervalo de tempo ela percorre maior distância? Analise cada uma das três situações.

c) O que você pode dizer a respeito da distância percorrida pela bola no decorrer do tempo? Qual é a relação entre a distância percorrida pela bola e o tempo de queda da mesma? Qual é a variável dependente e qual é a variável independente nesta relação?
Após estas questões o professor poderá questionar aos alunos se a posição da bola depende do tempo e se essa dependência pode ser formulada de outra maneira: o tempo de queda depende da posição da bola? Possivelmente esta última formulação gerará algumas discussões, mas depois de alguns questionamentos e mediações feitas pelo professor, é necessário que os alunos se convençam desta impossibilidade.

Neste momento, os alunos serão questionados a respeito do segundo gráfico, que relaciona a velocidade da bola e o tempo de queda, conforme exemplo ilustrado na figura 3.

Questão 4 - Analise o segundo gráfico de cada uma das três situações e responda às seguintes questões:

a) Sabendo que o eixo vertical do gráfico em questão refere-se à velocidade da bola em relação ao tempo, qual é a 


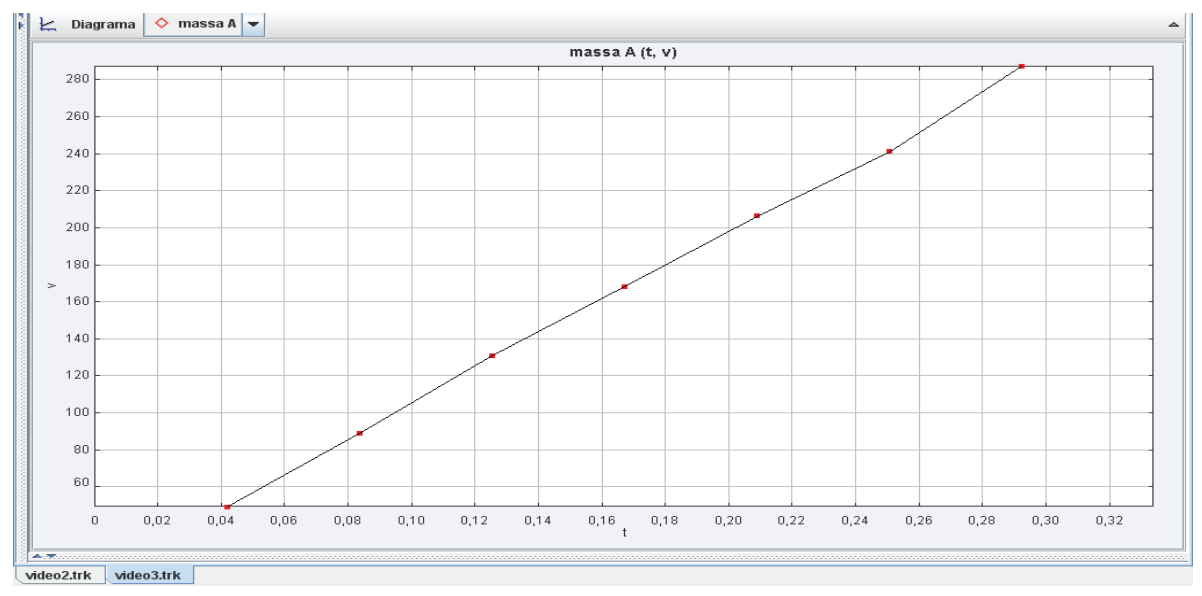

Figura 3 - Gráfico da velocidade em função do tempo, referente ao vídeo 3.

velocidade da bola no tempo 0 segundo?

As próximas questões têm por objetivo mostrar aos alunos qual é a relação existente entre as variáveis velocidade e tempo e qual é a relação entre a velocidade final de um corpo em queda livre e a altura em que foi abandonado. Além disso, os alunos poderão constatar que a velocidade aumenta proporcionalmente em relação ao tempo, sendo por este motivo que seu gráfico tende para uma reta.

\section{Questão 5 - Determine a} velocidade e a altura aproximada da bola em cada uma das situações no tempo $0,25 \mathrm{~s}$. Utilize os recursos do software para determinar estes valores com maior precisão.

Questão 6 - Você pode dizer que para cada valor do tempo existe um único valor para a velocidade e para a altura?
Questão 7 - Sabemos que, pelo fato das imagens não serem muito nítidas, existe, no momento de marcar os pontos de massa, a possibilidade de erro. Com isso, alguns valores em relação à velocidade podem apresentar pequenas distorções. Considerando isso, podemos dizer que o gráfico que mostra a velocidade da bola no decorrer do tempo tende a uma reta? Você pode dizer que a variação da velocidade é constante em relação ao tempo? Justifique sua resposta.

\section{Questão 8 - Observando os} gráficos da velocidade no decorrer do tempo em cada uma das três situações, em qual deles a bola apresenta a maior velocidade ao se aproximar do solo? E em qual das situações a bola apresenta a menor velocidade?

Questão 9 - Observando os gráficos de cada uma das três situações, em qual deles o movimento de queda ocorre em menor tempo? Podemos afirmar que, quanto maior for a posição 
inicial (altura) de um corpo em queda livre, maior será o tempo até sua chegada ao solo?

Questão 10 - O que podemos dizer a respeito da velocidade final de um corpo em queda livre em relação ao tempo de queda? E em relação à altura em que foi abandonado?

Questão 11 - Qual a relação entre a velocidade de um corpo em queda livre e o tempo de queda? Qual é a variável dependente e qual é a variável independente nesta relação?

Finalizadas estas questões, os alunos deverão perceber a relação de dependência entre as grandezas físicas envolvidas nas situações investigadas e, além disso, observar que para cada valor da variável tempo temos um único valor para as grandezas: altura e velocidade. Estes aspectos serão necessários para que o aluno tenha uma primeira noção de relação funcional.

Neste momento, o professor deverá questionar os alunos a respeito do fenômeno estudado e sua relação com o problema inicial que originou a experiência. Todas as questões até então formuladas e respondidas pelos alunos, darão ao professor condições de elaborar com eles uma primeira definição de função a partir da relação de dependência entre duas variáveis.

\subsection{A segunda atividade}

Nesta etapa, propomos a introdução de alguns conceitos presentes no estudo de funções afins e quadráticas. Para iniciar esta atividade, faremos o seguinte questionamento aos alunos:

"Quando jogamos um objeto para cima, este retorna ao solo após atingir uma altura máxima. Você saberia responder se a velocidade com que o objeto toca o solo é maior, menor ou igual a velocidade com que a bola foi arremessada?"

Para responder a essa questão, os alunos deverão produzir um vídeo ilustrando esta situação. Como sugestão, vamos utilizar neste trabalho um vídeo que mostra uma bola de tênis sendo lançada para cima, conforme ilustrado na figura 4.

Após a produção do vídeo, propomos algumas questões aos estudantes com o objetivo de construir uma definição para função afim e função quadrática, além de explorar alguns elementos importantes presentes no estudo destes dois tipos de função.

O professor deverá, inicialmente, fazer uma exploração dos gráficos e tabelas apresentados ao lado direto da janela principal do Tracker. O primeiro gráfico a ser explorado será o gráfico referente a componente $x$ da posição.

No programa Tracker, as posições de um objeto em relação ao seu deslocamento horizontal e vertical são chamadas, respectivamente, de componente $x$ e componente $y$. Assim, é importante que o professor explique que, em relação aos eixos que aparecem no vídeo, temos o eixo horizontal, representado pela componente $x$, e o eixo vertical pela componente $y$. No entanto, nos gráficos apresentados, teremos as duas componentes $x$ e $y$ analisadas separadamente e 
relacionadas com o tempo. Desta respectivos gráficos, também mostra a maneira, no $1^{\mathrm{o}}$ gráfico analisado, temos posição da bola em relação ao tempo. a componente $x$ apresentada no eixo $\mathrm{Na}$ primeira coluna temos o tempo, vertical e o tempo no eixo horizontal. E, medido em segundos, e nas demais no $2^{2}$ gráfico, a componente $y$ aparece colunas as posições da bola em relação no eixo vertical e o tempo no eixo às componentes $x$ e $y$, respectivamente, horizontal. O professor deverá mostrar medidas em centímetros. aos alunos que a tabela, logo abaixo dos

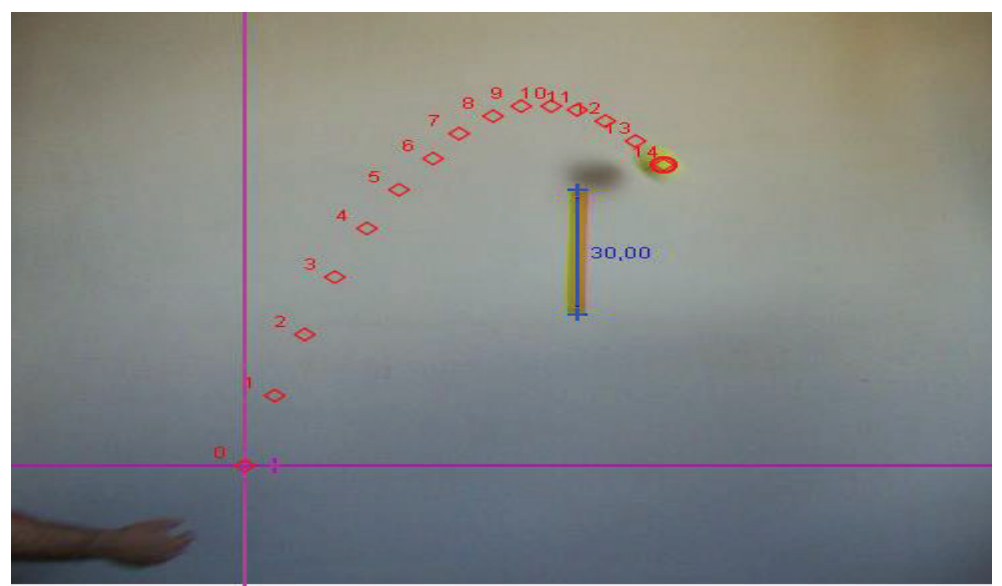

Figura 4 - Movimento oblíquo da bola de tênis

Na sequência, apresentaremos uma segunda atividade onde os alunos irão explorar o gráfico da componente $x$
(Figura 5) e a tabela de valores gerada a partir do movimento oblíquo da bola (Figura 6).

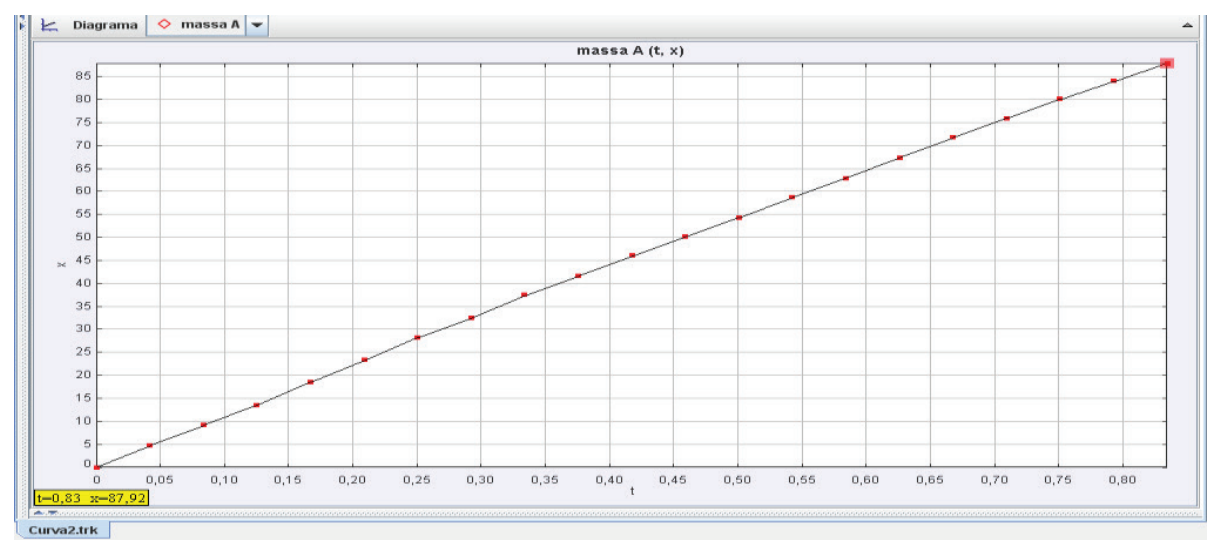

Figura 5 - Gráfico da componente x gerado pelo movimento oblíquo da bola. 


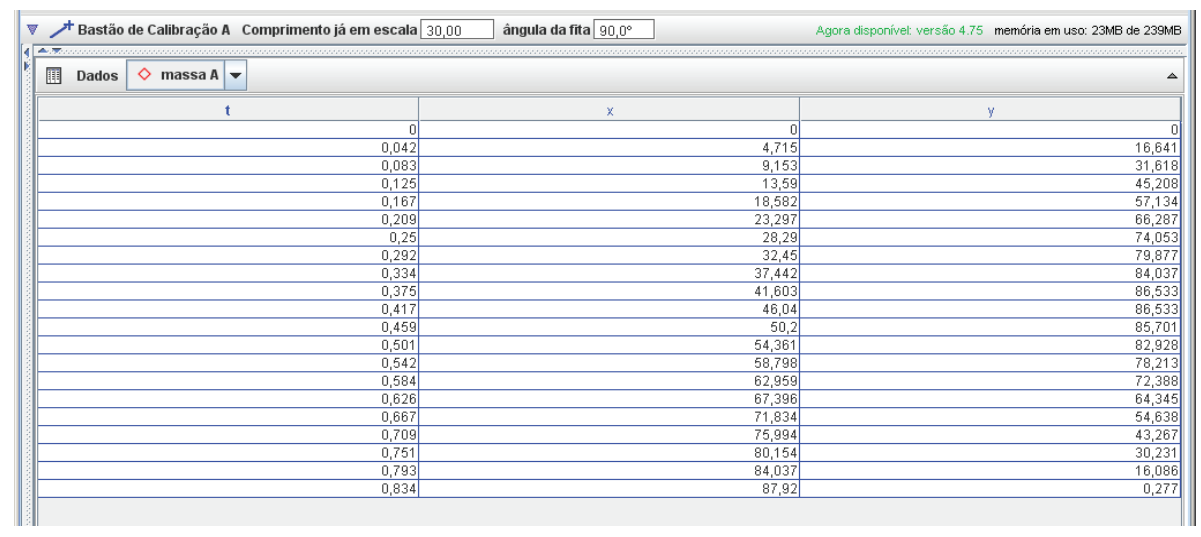

Figura 6 - Tabela de valores referentes ao movimento oblíquo da bola.

Questão 1 - Analise o gráfico da se você analisasse somente a tabela, componente $x$, a tabela de valores e também teria condições de responder à depois responda às questões que seguem: mesma pergunta?

a) Observando o gráfico da componente $x$, responda qual é a posição aproximada da bola após 0,50 segundos? E após 0,75 segundos?

b) Agora, observando a tabela responda às mesmas questões do item anterior.

c) Qual a distância percorrida pela bola nos 0,25 primeiros segundos? E nos 0,25 segundos subsequentes? Como você pretende obter estes dados?

d) Em que momento a bola atinge a marca de 45 centímetros? Esse é o único momento em que a bola atinge esta marcação?

e) Os dados da tabela correspondem aos mesmos valores encontrados no gráfico? Poderíamos, então, construir um gráfico utilizando os dados da tabela?

f) Observando o gráfico da componente $x$, você poderia responder qual é a variável dependente e qual é a variável independente nesta relação?

g) Como é a configuração gráfica da componente $\mathrm{x}$ no decorrer do tempo? $\mathrm{E}$ h) Em relação à análise feita no item anterior, é melhor fazê-la observando o gráfico ou a tabela?

Estas primeiras questões nos remetem, novamente, ao conceito de função e à construção do gráfico de funções afins. É importante que o aluno perceba que a partir dos dados de uma tabela podemos construir um gráfico, e que a visualização dos dados no gráfico pode facilitar a análise de seu comportamento. Além disso, questões como estas proporcionam ao aluno uma melhor compreensão das diferentes maneiras de representação de uma função, que neste caso referem-se a um fenômeno físico.

Questão 2 - Agora, vamos explorar os dados referentes a componente $y$.

a) Observe os dados da tabela em relação à componente $y$. Como é o comportamento destes valores em relação ao tempo? 
b) Se marcássemos os pontos correspondentes da tabela em um plano cartesiano, onde o eixo vertical indicasse a altura da bola (componente $y$ ) e o eixo horizontal indicasse o tempo, como seria sua configuração gráfica?

c) Desenhe o gráfico desta situação em um papel e depois confira sua construção com o gráfico gerado pelo programa. Para obtê-lo, você deve clicar no gráfico em cima da componente $x$, onde abrirá uma janela possibilitando a mudança para a componente $y$. os alunos respondam à seguinte questão:

Questão 3 - Observando o gráfico da componente y responda:

a) No decorrer do tempo, como é o comportamento da altura da bola aqui representada pela componente $y$ ?

b) Podemos dizer que a altura varia com o decorrer do tempo?

c) Se a altura varia com o tempo, então podemos afirmar que, nesta situação, a altura é dada em função do tempo? Podemos dizer, também, que o tempo

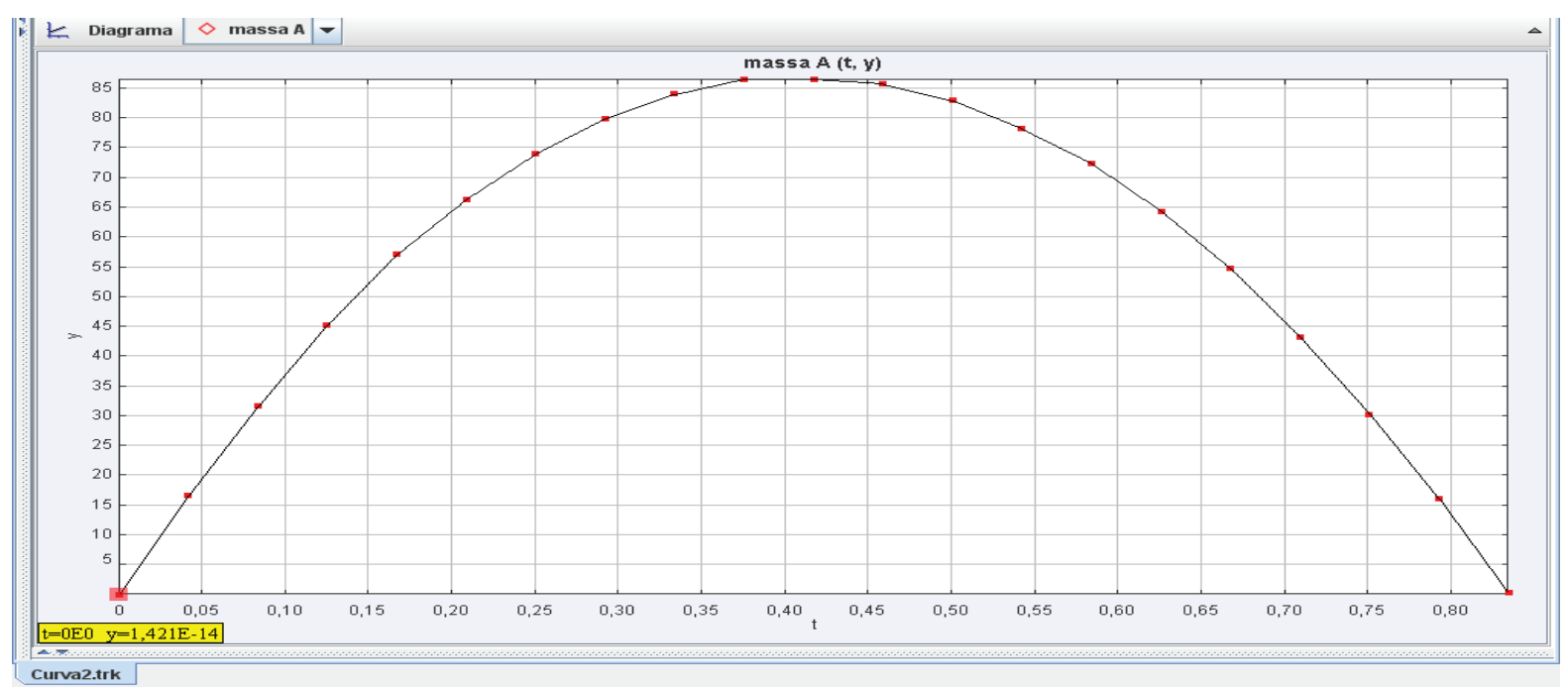

Figura 7 - Gráfico do movimento da bola em relação a componente y.

No momento em que é apresentada a configuração gráfica da componente y (Figura 7), o professor deverá falar aos alunos que o nome dado a este tipo de curva é parábola, podendo fazer referência a outros exemplos onde esta configuração também aparece.

Conhecendo a configuração gráfica do movimento da bola em relação à componente $y$, sugerimos que está em função da altura? Justifique suas respostas.

Com estas três questões, pretendemos, novamente, reforçar entre os alunos a noção do conceito de função. Entendemos que é importante para eles perceberem a relação entre as variáveis envolvidas em várias situações. Sendo assim, no decorrer de toda nossa proposta, estas questões serão retomadas a fim de questioná-los a 
respeito desta relação e quais delas, efetivamente, podem ser tomadas como uma relação funcional.

Além da relação funcional, pretendemos, com a primeira questão, introduzir ideias relacionadas ao crescimento e decrescimento de uma função.

$\mathrm{Na}$ questão 4, pretendemos explorar intuitivamente a noção de valor funcional, valor máximo de uma função, simetria da parábola e as diferenças existentes na representação gráfica de uma função afim $\mathrm{e}$ quadrática.

Questão 4 - Observando o gráfico do movimento da bola em relação à componente $y$ ou os dados da tabela, responda:

a) Qual é, aproximadamente, a altura máxima atingida pela bola?

b) O tempo de subida é igual ao tempo de descida da bola?

c) Em que momento a bola atinge a altura de 45 centímetros?

Esta última questão deverá ser comparada com a mesma questão feita anteriormente na análise do movimento em relação à componente $x$. Espera-se que os alunos percebam que na função afim, onde o gráfico é uma reta, temos um único valor da componente $x$ para cada valor do tempo, uma vez que a bola se desloca sempre para a direita. E quando a função tem como configuração gráfica uma parábola, temos para cada valor da componente $y$ até dois valores para o tempo, uma vez que a bola sobe e depois desce.

Nas próximas questões, vamos novamente abordar a noção de relação funcional, só que agora relacionando velocidade e tempo.

Questão 6 - Observe novamente as imagens do movimento da bola sendo lançada para cima.

a) A bola foi lançada com uma velocidade inicial e depois de atingir sua altura máxima retorna ao solo. Como se comporta a velocidade da bola no decorrer do movimento? Podemos dizer que a velocidade varia com $\mathrm{o}$ tempo? Em caso afirmativo, determine os intervalos onde ela é crescente, decrescente ou constante.

b) Qual é a relação de dependência entre o tempo e a velocidade da bola no decorrer do movimento?

Questão 7 - No momento em que a bola atinge a altura máxima, como deve ser sua velocidade: igual ou diferente de zero?

Questão 8 - Após responder a estas questões, tente imaginar e desenhar no papel como deve ser o gráfico que relaciona a velocidade com o tempo no decorrer do movimento.

$\mathrm{Na}$ sequência os alunos irão explorar o gráfico da velocidade em função do tempo (Figura 8), propomos para tanto algumas questões.

Questão 9 - Observando o gráfico gerado pelo Tracker, analise as respostas formuladas por você anteriormente e, se necessário, reescreva corretamente as que estão erradas.

Questão 10 - Ainda em relação ao gráfico da componente velocidade, percebemos que a curva é côncava para 
cima, diferente do gráfico da componente y. Explique por que isso acontece.

Questão 11 - Percebendo que a velocidade não é constante no decorrer do tempo, escreva os intervalos onde a função é crescente e decrescente.

Questão 15 - Faça uma pequena pesquisa a respeito da questão anterior nos livros de Física ou na internet e verifique se as conclusões são as mesmas que você encontrou. Caso sejam diferentes, tente explicar por que isso aconteceu.

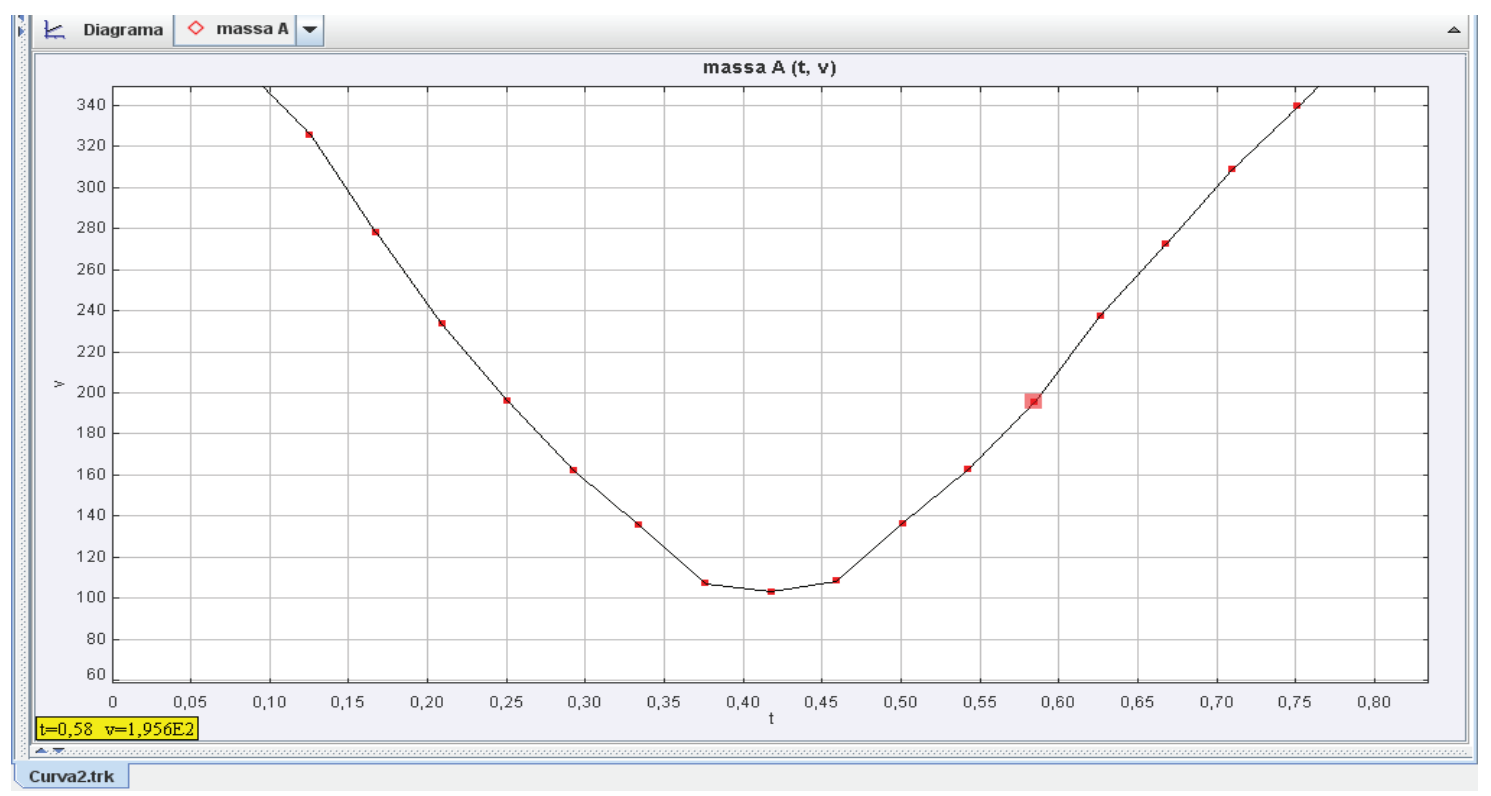

Figura 8 - Gráfico da velocidade em função do tempo.

Questão 12 - Qual é a velocidade inicial, a velocidade final e a velocidade mínima atingida pela bola?

Questão 13 - Compare o instante em que a bola atinge a velocidade mínima com o instante em que a bola atinge sua altura máxima e escreva o que você pode observar.

Questão 14 - Em relação à questão inicial: "a velocidade com que o objeto toca o solo é maior, menor ou igual a velocidade com que a bola foi arremessada?", o que você responderia agora?
Questão 16 - Observe que nos tempos 0,375 s e 0,417 s apesar dos valores da componente y permanecerem iguais, os valores da velocidade são diferentes. Tente explicar por que isso acontece.

Acreditamos que estas últimas questões cumprem perfeitamente o papel que o ensino deve ter na formação dos educandos, que é a de incentivar o aluno a ser investigador, criativo, desenvolver sua criticidade e ser agente participativo na construção de seu próprio conhecimento. 
A questão 17, tem como objetivo inquirir os alunos a respeito das diferenças entre as situações apresentadas na $1^{\underline{a}}$ e $2^{\underline{a}}$ atividades e novamente incentivá-los a investigar os movimentos estudados também do ponto de vista físico.

\section{Questão 17 - Analise as situações} das duas atividades realizadas e responda:

a) Por que, na primeira atividade desenvolvida, exploramos somente o gráfico da componente $\mathrm{y}$, e na segunda atividade exploramos os gráficos das componentes $x$ e $y$ ?

b) O gráfico da velocidade em função do tempo, na $1^{\underline{a}}$ atividade, se assemelha a uma reta e, na $2^{\text {a }}$ atividade, a uma parábola côncava para cima. Tente explicar, com suas palavras, por que isso acontece.

c) Faça uma pesquisa sobre a questão anterior buscando encontrar as fórmulas do movimento em queda livre e do movimento oblíquo, destacando as variáveis físicas presentes nestes movimentos. Da posse destas fórmulas, procure relacioná-las e testá-las nas situações estudadas e verifique se os resultados, em relação à velocidade em determinados tempos, são semelhantes aos obtidos pelo Tracker.

Estas questões podem dar início a um trabalho interdisciplinar, o qual poderá ser desenvolvido em parceria com as disciplinas de Matemática e Física. É bem provável que, após estas experiências, os alunos modifiquem também seu pensar sobre a matemática, percebendo sua importância para

descrever e compreender também os fenômenos físicos.

Ao aprofundar o estudo do movimento oblíquo da bola do seu ponto físico o professor poderá, inclusive, introduzir o estudo de vetores de um modo significativo e interessante. Ao decompor o movimento da bola nas direções horizontal e vertical, percebemos dois tipos de movimentos. A componente horizontal da velocidade permanece constante durante todo o tempo, caracterizando um movimento retilíneo e uniforme. Já em relação à componente vertical da velocidade, temos um movimento retilíneo uniformemente variado: retardado, do inicio do movimento até atingir a altura máxima; e acelerado, do ponto de altura máxima até o final do movimento. Como os dois movimentos são simultâneos, a sua decomposição determina a trajetória parabólica realizada pela bola.

Terminada esta atividade, o professor deverá explorar com os alunos a definição de função mais formal e dar uma primeira noção de função afim e quadrática relacionadas com seus aspectos gráficos, sempre fazendo referência às duas primeiras situações de movimento analisadas pelo programa Tracker. Acreditamos que depois desta abordagem contextualizada e interdisciplinar, a apresentação mais formal de definições e outros conceitos matemáticos presentes no estudo de funções serão melhor compreendidos pelos alunos.

\section{Conclusões}


Acreditamos que a proposta aqui apresentada é apropriada para a introdução do estudo de funções e tem um caráter diferenciado, que pode ser comprovado em cada uma das atividades, principalmente em relação ao modo como os saberes são introduzidos. As questões vão delineando um caminho que leva, gradativamente, à formulação dos conceitos e definições. Uma inovação foi a introdução do software Tracker no ensino da matemática, desenvolvido e comumente utilizado para o ensino da Física, o que serviu perfeitamente para a exploração do conceito de função.

Apesar da proposta ter características diferenciadas e sua abordagem possibilitar uma maior compreensão dos conceitos relacionados ao estudo de funções, esta não pode ser concebida como uma receita que garante a aprendizagem. $\mathrm{O}$ processo de ensino e aprendizagem depende de muitas variáveis, a forma como o professor conduzirá as atividades, por exemplo, é crucial para que os objetivos da proposta sejam completamente atendidos. Esta proposta é, portanto, uma abordagem para o ensino de funções sujeita a adaptações, correções e reformulações.

Durante a elaboração das atividades, percebemos que uma simples situação-problema pode gerar uma ótima oportunidade para a introdução e desenvolvimento dos conteúdos escolares. Assim sendo, acreditamos que muitas das mudanças sugeridas e esperadas para o ensino da matemática podem surgir de ideias simples somadas à disposição do professor em aceitar novos desafios, ousar, experimentar diferentes metodologias e criar novas estratégias.

A cada dia que passa, mais escolas estão sendo equipadas com computadores e outras tecnologias. $\mathrm{O}$ professor, por sua vez, deve estar preparado para utilizar adequadamente estes recursos, promover não somente a inserção dos alunos no mundo tecnológico, mas acima de tudo garantir que estes entes promovam a aprendizagem de novos saberes.

Outra sugestão para complementar a atual proposta é criar uma comunicação direta entre a Matemática e a Física, no sentido de desenvolver os conteúdos pertinentes às duas disciplinas mediante a exploração do mesmo problema ou situação. A exploração de alguns conceitos e o desenvolvimento dos conhecimentos físicos poderiam ser realizados a partir da análise dos mesmos movimentos abordados nas atividades com o Tracker e na elaboração de questões pertinentes a estes assuntos. A dedução das fórmulas, por exemplo, poderia ser realizada a partir da análise dos movimentos e fundamentada nas observações já realizadas e alguns conhecimentos matemáticos. Esta sugestão pretende desenvolver um ensino voltado à articulação dos saberes e se opõe ao saber compartimentado e fragmentado, onde o aluno não percebe as conexões existentes entre as diversas áreas do conhecimento.

Concluindo, esperamos que este trabalho possa contribuir, de alguma forma, para o ensino da matemática e mais especificamente, para o ensino de funções. Pretendemos, além de oferecer aos professores uma nova metodologia 
para o ensino de funções, oportunizar um momento de reflexão sobre sua prática pedagógica e a busca de alternativas para a melhoria da educação através da matemática.

\section{Referências}

BRASIL. Parâmetros curriculares nacionais: ensino médio. Brasília: MEC, 2000

COSTA, A. C. Conhecimentos de estudantes universitários sobre o conceito de função. 2004. 92 f. Dissertação (Mestrado em Educação Matemática) - Pontifícia Universidade Católica de São Paulo, São Paulo, 2004.

COSTA, C. B. de J. da. O conhecimento do professor de matemática sobre o conceito de função. 2008. 96 f. Dissertação (Mestrado em Ensino de Matemática) - Universidade Federal do Rio de Janeiro, Rio de Janeiro, 2008.

MAGARINUS, R. Estudo de funções: compreensões e aprendizagem de alunos do ensino médio. 2006. $71 \mathrm{f}$. Monografia (Especialização em Educação Matemática) - Universidade de Passo Fundo, Passo Fundo, 2006.

MARIANI, R. de C. P. O estudo de funções: uma análise através dos registros de representação semiótica. Educação Matemática em Revista R.S., n. 6, p. 49-58, dez. 2004.
ZUFFI, E. M. Alguns aspectos do desenvolvimento histórico do conceito de função. Educação Matemática em Revista, São Paulo, n. 9/10, p.10-16, abr. 2001.

ZUFFI, E. M.; PACCA, J. L. Sobre funções e linguagem matemática de professores do ensino médio. Zetetiké, Campinas: UNICAMP, v. 8, n. 13/14, p. 7-28, jan./dez. 2000.

\section{.}

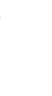

